\title{
The Design Factors of Cosmetic Packaging Textures for Conveying Feelings
}

\author{
Siripuk Ritnamkam ${ }^{1} \&$ Yada Chavalkul ${ }^{1}$ \\ ${ }^{1}$ Faculty of Architecture, King Mongkut's Institute of Technology Ladkrabang (KMITL), Bangkok, Thailand \\ Correspondence: Siripuk Ritnamkam, Multidisciplinary Design Research, Faculty of Architecture, King \\ Mongkut's Institute of Technology Ladkrabang, Bangkok, Thailand. Tel: 66-63-2465-323. E-mail: \\ siripuk_pum@hotmail.com
}

\author{
Received: July 31, $2017 \quad$ Accepted: August 30, $2017 \quad$ Online Published: September 28, 2017 \\ doi:10.5539/ass.v13n10p86 URL: https://doi.org/10.5539/ass.v13n10p86
}

\begin{abstract}
There have been a lot of studies on the relationship between visual appearances of packaging-such as color, font, and illustration - and consumers' feelings, but very few focused on touch sensation. Well-designed touch texture can attract consumers to cosmetic products and can be considered as a rarely-explored way of sensory marketing. The objectives of this study was to seek for design factors (design elements that can be associated with feeling words). Thirty-six different 3-D texture models were constructed. Their designs were produced from established 2-D visual design elements. Those models were tested by a group of participants to see whether they could clearly convey different feelings. Only 6 models were deemed valid in this sense. These 6 models were then sought for distinctive design factors. The 5 design factors that were obtained were the following: 1) structure of lines, 2) distance between lines, 3) small and large empty spaces, 4) line uniformity, and 5) number of lines. These design factors were able to elicit 16 feeling words: 1. Busy, 2. Tense, 3. Strong, 4. Confident, 5. Manful, 6. Delicate, 7. Friendly, 8. Gentle, 9. Sensitive, 10. Enjoyable, 11. Independent, 12. Natural, 13. Simple, 14. Comfortable, 15. Easy, and 16. Flexible. These design factors can be directly used by designers for constructing textured surface components of packages or products that can affect consumers' feelings by touch.
\end{abstract}

Keywords: factor, texture, consumer, feeling word, cosmetic package

\section{Introduction}

Human senses_-vision, touch, taste, smell, and hearing-greatly affected consumers' perceptions of a product. Perceptions are based on personal experiences, demographic characteristics, and culture and lead to certain emotional responses. A positive response can lead to a decision to buy the product whereas a negative response may result in avoidance of it (Crilly, Moultrie, \& Clarkson, 2004). The texture of a package is a stimulus for touch sensation. Consumers' responses to this sensation can affect their purchasing behavior. This study investigated various kinds of textures of cosmetic package that can affect the perception and feeling of consumers as they touch them.

The physical characteristics of a package can function to communicate some information about the product to users. They are also used to position a product and to convey its selling point; that is, they can show the 3 main marketing components: brand, target, and product (Jirapinyo, 2015). These 3 components are mediated by various senses. The sense of sight has been widely researched for the purpose of stimulating consumers to buy a product at a retail channel. For example, Ritnamkam \& Sahachiseree (2012) investigated various visual design factors of cosmetic package (color, shape, font, illustration, graphics, and material) that might express gender and how they differently affected consumers' perception. Her hypothesis was that a particular design factor would influence the participants to feel that it expressed masculinity or femininity which, in turn, would affect consumers' purchasing intention. With respect to sense of taste, Smets \& Overbeeke (1995) investigated visual design factors for package of sweets and their association with taste sensation. The author asked the participants to taste the sweets and then suggest the color and shape for the package. Becker, Rompay, Schifferstein \& Galetzka, (2010) performed a similar study with a yoghurt product. Ludden \& Schifferstein (2009) investigated the sense of smell. The author asked the participants to smell a biscuit product and then suggest the shape of the package. This usage of the senses of smell and taste is a new research direction that can benefit future designers.

Touch sensation can complement visual sensation in attracting consumers to a product. This is the reason why 
marketers are willing to have consumers touching a product in order to positively influence their purchasing decision (Marlow \& Jansson-Boyd, 2011). McDougall (2010) investigated visual sensation and consumers' interest in a product. The author focused on designing distinctive package in terms of visual and touch sensations in order to attract the interest of consumers and influence their purchasing decision. Therefore, it has been shown that touch sensation can affect the feeling of consumers towards a product. However, this sense has not been investigated in isolation to other senses with respect to package design until the author has done a pilot study that demonstrated that touch sensation of diverse texture designs of a cosmetic package was able to convey diverse feelings (Ritnamkam \& Chavalkul, 2016). For example, she found that textures with protruded patterns were able to convey the feelings of gentleness, cheerfulness, child-likeness, cuteness, and adolescent-likeness.

The main objective of this study was to seek for textural design factors that designers can use to construct textured surface components of packages that can influence consumers' feelings by touch.

\section{Literature Review}

This study was based on the concept of significance of senses over the feeling towards a product, originated by (Crilly, Moultrie, \& Clarkson, 2004) Crilly stated that consumers' perceptions are based on the senses that affect their emotional responses. A positive response can lead to a decision to buy the product while a negative response may result in a decision not to buy it. Crilly's conceptual model comprised the product, the 5 senses (vision, touch, taste, smell, and hearing), the affect, and the purchasing behaviour.

This study investigated the affectual response of consumers after they have touched a textured surface. Compared to the conceptual model of Crilly, Crilly's product was like the textured surface studied, Crilly's sense was like the touch sense in this study, and Crilly's affect was like the affectual response obtained in this study, as diagrammed in Fig. 1.

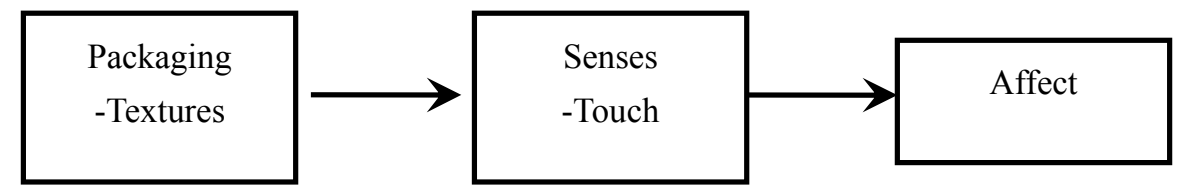

Figure 1. The main part of Crilly's conceptual model

Therefore, the sought for design factors in this study that affected consumers' feelings were related to 3 main variables: texture, consumer, and feeling words. As can be compared between Fig. 1 and Fig. 2, packaging texture was the same as texture; sense of touch was the same as consumer (after they have touched the textured surface); while affect was the same as feeling words.

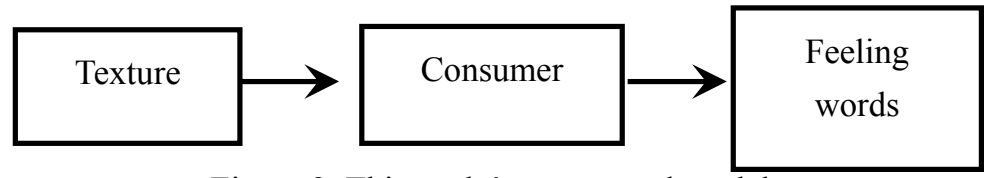

Figure 2. This study's conceptual model

\section{Methodology}

To reach the objective, the researcher has used a qualitative approach to obtain the feeling words. Sample groups were interviewed after they had touched the surface of cosmetic packages. Their words from the interviews were used to find the design factors that affected their feelings. In order to clarify the 3 main steps in the methodology, they are described together with some results from the previous step, as follows: Step 1: Construction of models with various kinds of texture; Step 2: Testing the quality of the constructed 3-D models; and Step 3: Seeking for valid design factors from the models that has passed the quality test in Step 2.

\section{Step 1: Constructing textures}

The texture construction consisted of only 1-mm-thick lines. They were a constant factor. Independent variables were five 2-dimensional visual design elements. These visual elements were used because they have already been extensively researched in regard to affect and the texture constructed should inherit their design qualities. Viewing from the top, these design elements looked the same as 2-D elements. The only difference was their height or protuberance from the surface. Therefore, the 5 constructed design factors were the following: lines (which were primarily used to define structures in this study), distance between lines, small and large empty spaces, line uniformity, and number of lines. These were independent variables that caused the participants to respond with feeling words which were dependent variables. 
Six kinds of structures were used: 1) a structure with an emphasis on horizontality and verticality, 2) a structure with a curvilinear dominant, 3) a structure with an emphasis on diagonality, 4) a structure with radial burst, 5) a structure with an emphasis on line orientation in opposite directions3), and 6) a structure with lines evenly spread all over the plane. These structures of lines had spaces in them. Space, here, means the area between lines or the area that surrounds lines. Space depends on distance between lines and number of lines. The bigger the space the shorter the distance between lines and the lower the number of lines. Lines could also be distributed uniformly or non-uniformly which would give different affectual responses (Chavalkul, 2003).

The length and width of the models of packaging were $7.5 \times 7.5 \mathrm{~cm}$. This size was found to be the average size of compact cases in the local market (Thailand). A lot of designs were constructed then screened by a 2-D graphic designer expert. Thirty six 2-D designs in all were obtained, shown in the Appendix. In there, the designs were grouped in 6 groups: Group A consists of structures with an emphasis on horizontality and verticality, Group B consists of structures that are curvilinear dominant, Group $\mathrm{C}$ consists of structures with an emphasis on diagonality, Group D consists of structures with radial burst, Group E consists of structures with an emphasis on contrast of line orientation, Group F consists of structures with an even spread of lines. These constructed 2-D designs were used to construct 3-D models by representing the lines by 1-mm threads.

\section{Step 2: Testing the quality of the 3-D models}

The models were tested by a sample group whether the 3-D tactile aspect of them were clearly sensed by the group. The sample group were students at the Faculties of Science and Architecture in King Mongkut's Institute of Technology Ladkrabang who were the target group of cosmetic products and whose ages were between 18 to 34 years old. The reason for choosing a group from the Faculty of Science and a group from the Faculty of Architecture was that the former group had no art-and-design-based background while the latter had it which influenced the feeling words that they uttered in a pilot study (Ritnamkam \& Chavalkul, 2016). The latter group was able to respond to textures with more diverse feeling words. In order to represent the totality of consumers that may sense the textures, both groups were included for the test. The test was done in 2 rounds. The quality of the models was tested by 5 participants in each round. The reason for the small number of participants was that the author needed to be able to have an in-depth interview with each participant in order for them to clearly explain the textures that they felt in a large variety of feeling words.

In the first round, the test was to have the participants described the quality of the textured surface, and the passing criterion was that more than 2 out of 5 participants were able to describe them successfully. The 3-D models that passed the criterion were kept for using in the design factors seeking step, while the models that could not be described clearly were then improved on and tested again in the second round together with the original ones.

In the second round, a new participant group tested the 3-D models. A new group was needed because it was found in the pilot study that improved models had always been correctly identified when the group had had an experience with the original ones. The test procedure and the passing criterion were the same as those of the first round, but only applied to the models that did not pass the first round with their improved version. The 3-D models that passed this last round of Step 2, 36 in all, were then used in the next step, i.e., for seeking the design factors.

\section{Step 3: Seeking for distinctive design factors}

The sought for design factors were related to the 3 independent variables: texture, consumer, and feeling words. After the participants touched the texture, they were asked to describe their feeling towards it with a word. The feeling word was then identified with every design element in the model. The correspondence between the design elements and feeling words was examined to establish design factors, diagrammed in Fig. 3, comprised the following 2 stages.

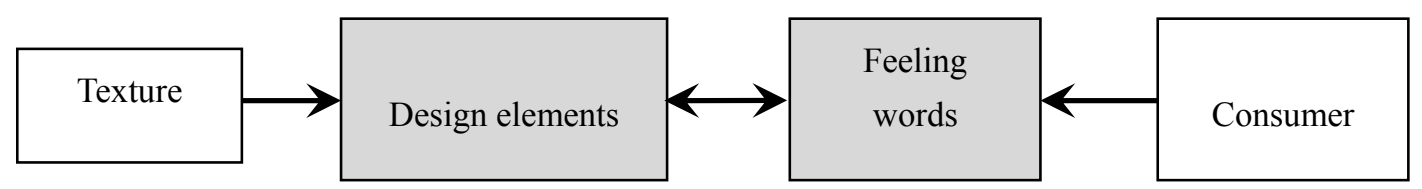

Figure 3. Identification of design factors

Stage 1: Obtaining feeling words describing the textures from participants

Sample group: The selection criterion to include both the students with and without a design background for this sample group was the same as that stated in Step 2. However, this group is 30 participants (15 students each with 
design and non-design background). The reason for a bigger group at this stage was that the author wanted to have more opinions on the topic and this number has been suggested as a practical minimum for social science research (Denscombe, 2010).

Method: Every participant was asked to touch 36 texture models that were randomly arranged without any numeric label. Each model was visually hidden in a box. Each time a participant touched a model, he or she was asked to respond with a feeling word and if his or her feeling towards a particular model was similar to the feeling he or she had with other models he or she had previously touched, the participant was asked to divide the models into groups that were described by the same word.

Results: From all participants, 1080 feeling words were obtained (36 models x 30 participants). Each participant provided 1 word for 1 texture model. Some of these 1080 words were not semantically different from each other. Therefore, in the next stage (Stage 2, Phase 1), they were grouped under different headings.

Stage 2: Seeking for design factors, this stage was done in 2 phases as follows:

Phase 1: Putting similar words acquired in Stage 1 into groups. This is to collect texture models that the participants had the same feeling.

Sample group: The criterion for sample group selection was the same as that performed in Step 2 but only 3 participants were needed because data collection with the small number of participants allowed the researcher to justify the grouping of 1,080 words whose meaning are similar.

Method: Each of the 3 participants looked at the 30 words that described each model and put these words into different groups where a group consisted of words with similar meaning. The purpose of this method was to acquire the group of a largest number of similar words which would show that the model described by these words was worthy of further use.

Passing criterion: A model would be included for further use if two or more participants out of three had grouped the 30 words acquired for each model into a big group with ten or more similar words. The rationale behind this passing criterion was that the model that could be described by a large number of similar words should be able to convey that meaning well, and so it should be included as a valid model for that description and could be further sought for valid design factors.

Results: The models that passed the criterion were the following: A6 that consisted of a structure with an emphasis on horizontality and verticality, B9 that consisted of a structure that were curvilinear dominant, C13 that consisted of a structure with an emphasis on diagonality, D20 that consisted of a structure with radial burst, E25 that consisted of a structure with contrasting line orientation, and F34 that consisted of a structure of lines evenly spread, as shown in Fig. 4.

A sample of words similar to busy and tense that a participant put into the same group are as follows: cramped, busy, tense, confusing, disorderly, discordant, uneven, incomplete, stressed out, weak, infrequent, informal, unresolved, unfinished, not predestined, and spread out.
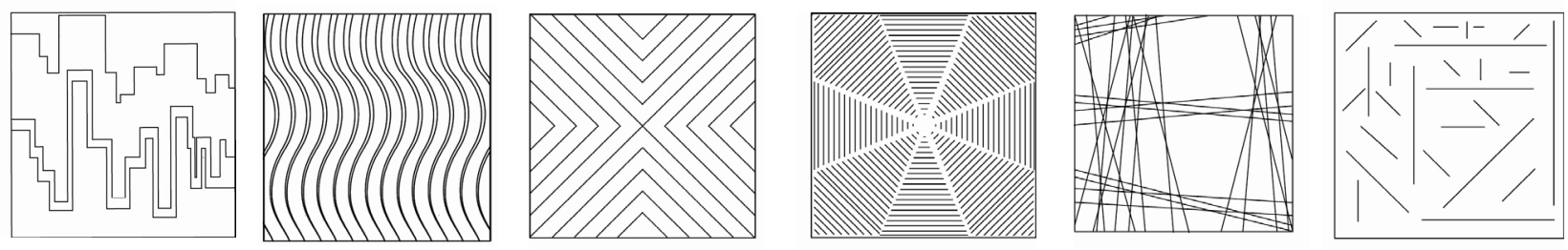

Figure 4. The textures of valid models

Phase 2: Matching design elements and feeling words.

Method: The researcher identified the design elements in each valid model acquired in Phase 1 that matched the corresponding feeling words, model by model. The researcher attempted to identify the design elements that corresponded with all feeling words that at least two out of three participants had chosen. Then, the design factors, the design elements that the participants expressed the particular feelings, was defined.

Results: It happened that the textures of the models A6, B9, D20, and E25 elicited the same feeling word from all 3 participants, while the textures of the models F4 and C13 elicited the same feeling word from 2 out of 3 participants. These models and their associated feeling words can be seen in Table 1. The author then identified the design elements of these models as follows: 
1. The busy and tense feelings associated with model A6 were expressed by these design elements: 1) a structure with an emphasis on horizontality and verticality, 2) uneven distance between lines, low line frequency, 3) large empty space between lines, 4) line non-uniformity, and 5) small number of lines.

2. The strong and confident feelings associated with model B9 were expressed by the following design elements:

1) a structure that were curvilinear dominant, 2) even distance between lines, high frequency of lines, 3) small space between lines, 4) line uniformity, and 5) large number of lines.

3. The strong confident and manful feeling associated with model $\mathrm{C} 13$ were expressed by the following design elements: 1) a structure with an emphasis on diagonality, 2) even distance between lines, high frequency of lines, 3) small space between lines, 4) line uniformity, and 5) large number of lines.

4. The strong and delicate feelings associated with model D20 were expressed by the following design elements: 1) a structure with radial burst, 2) even distance between lines, high frequency of lines, 3) small space between lines, 4) line uniformity, and 5) large number of lines.

5. The friendly, gentle, sensitive, enjoyable, independent, and natural feelings associated with model E25 were expressed by the following design elements: 1) a structure with an emphasis on contrasting line orientation, 2) uneven distance between lines, low frequency of lines, 3) large space between lines, 4) line non-uniformity, and 5) small number of lines.

6. The simple, friendly, easy, comfortable, and flexible feelings associated with model F34 were expressed by the following design elements: 1) a structure with an even spread of lines, 2) uneven distance between lines, low frequency of lines, 3) large space between lines, 4) line non-uniformity, and 5) small number of lines.

It can be seen in Table 1 that some different models elicited the same feeling words.

For example, model B9, C13, and D20 elicited the feeling word of 'strong'. Interestingly, these models differed only in their overall structures. The design elements that were common to all were the following: 1) even distance between lines, high frequency of lines, 2) small space between lines, 4) line uniformity, and 5) large number of lines.

As another example, model B9 and C13 elicited the feeling word of 'confident'. The design elements that were common to both models were the following: 1) even distance between lines, high frequency of lines, 2) small space between lines, 3) line uniformity, and 4) large number of lines.

Table 1. Models and their associated feeling words.

\begin{tabular}{|c|c|c|c|c|c|c|}
\hline \multirow{2}{*}{$\begin{array}{l}\text { The textures of } \\
\text { valid models }\end{array}$} & \multicolumn{5}{|c|}{ design elements } & \multirow[b]{2}{*}{ feeling words } \\
\hline & 1. structure & $\begin{array}{c}\text { 2. distance } \\
\text { between lines }\end{array}$ & $\begin{array}{l}\text { 3. space } \\
\text { between } \\
\text { lines }\end{array}$ & 4. line uniformity & $\begin{array}{l}\text { 5. number } \\
\text { of lines }\end{array}$ & \\
\hline A6 & \multirow[b]{2}{*}{$\begin{array}{l}\text { a structure with } \\
\text { an emphasis on } \\
\text { horizontality } \\
\text { and verticality }\end{array}$} & \multirow[b]{2}{*}{$\begin{array}{l}\text { uneven } \\
\text { distance } \\
\text { between } \\
\text { lines, } \\
\text { low line } \\
\text { frequency }\end{array}$} & \multirow[b]{2}{*}{$\begin{array}{l}\text { large empty } \\
\text { space } \\
\text { between } \\
\text { lines }\end{array}$} & \multirow[b]{2}{*}{$\begin{array}{c}\text { line } \\
\text { non-uniformity }\end{array}$} & \multirow[b]{2}{*}{$\begin{array}{c}\text { small } \\
\text { number of } \\
\text { lines }\end{array}$} & participant $3 / 3$ \\
\hline $\begin{array}{l}3 \\
3 \\
3\end{array}$ & & & & & & busy, tense \\
\hline
\end{tabular}

B9

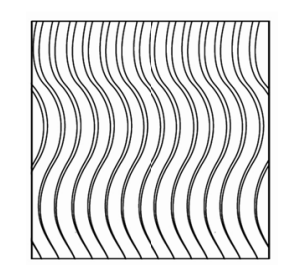

even distance

between

lines, high

frequency of

lines small space

between

lines

line uniformity

large

number of

lines strong,

confident 
C13

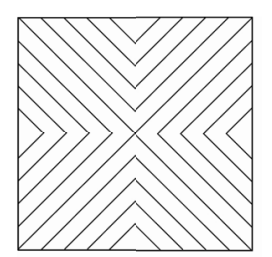

a structure with

an emphasis on

diagonality even distance

between

lines, high

frequency of lines participant $2 / 3$

small space
between
lines

strong, confident, manful
large
number of
lines

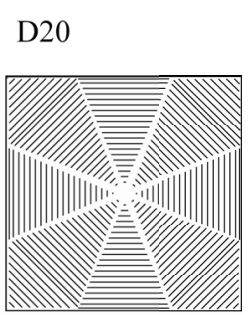

a structure with radial burst even distance

between

lines, high

frequency of

lines small space line uniformity

between

lines

line uniformity \begin{tabular}{ll} 
large & participant 3/3 \\
\cline { 2 - 2 } number of & strong, delicate
\end{tabular}

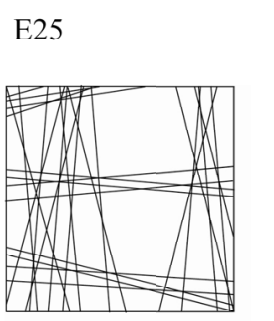

a structure with

an emphasis on

contrasting line

orientation

uneven

distance

between

large space

line

between

non-uniformity

lines, low

frequency of

lines

small

number of

friendly, gentle,

lines

sensitive,

enjoyable,

independent,

and natural

lines

F34

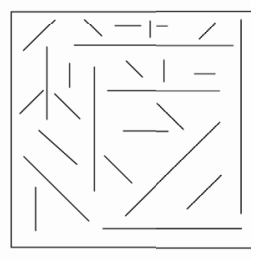

a structure with

an even spread

of lines uneven

distance

between

lines, low

frequency of

lines,

\section{Conclusion}

From our investigation of textured surfaces of packages that affected consumers' feelings, 5 design factors were obtained: 1) structure of lines, 2) distance between lines, 3) small and large empty spaces, 4) line uniformity, and 5) number of lines. These design factors were able to elicit 16 feeling words: 1. Busy, 2. Tense, 3. Strong, 4. Confident, 5. Manful, 6. Delicate, 7. Friendly, 8. Gentle, 9. Sensitive, 10. Enjoyable, 11. Independent, 12. Natural, 13. Simple, 14. Comfortable, 15. Easy, and 16. Flexible. Some of these words were close in meaning, so they were grouped together below under certain design factors.

The 3-D models that had 4 of the same design factors-1) uneven distance between lines, low frequency of lines, 2) large space between lines, 3) line non-uniformity, and 4) small number of lines-but differed only in the structure of lines elicited the following feeling words. The model that had a structure with an emphasis on horizontality and verticality and the 4 design factors above elicited the feeling words of busy and tense. The model that had a structure with an emphasis on line orientation in opposite directions elicited the feeling words of friendly, gentle, sensitive, enjoyable, independent, and nature. The model that had a structure with lines evenly spread all over the plane elicited the feeling words of simple, friendly, comfortable, easy, and flexible. On the other hand, the 3-D models that had 4 of the same design factors that were the opposite of the 4 design factors mentioned above-1) even distance between lines, high frequency of lines, 2) small space between lines,3) line uniformity, and 4) large number of lines-elicited the following feeling words. The model that had a structure that 
is curvilinear dominant and the latter 4 design factors elicited the feeling words of strong and confident. The model that had a structure with an emphasis on diagonality elicited the feeling words of strong, manful, and confident. The model that had a structure with radial burst elicited the feeling words of strong and delicate.

\section{Discussion}

In our investigation of textured surfaces that affected consumers' feelings, we brought in 2-D design elements that had been established to affect consumers' feelings in one way or another. The first type of element that was brought in was various structures of lines because these structures could be easily distinguished by sight (Chavalkul, 2003). However, these structures in the 3-D models were not easily distinguishable by touch.

It turned out that the easily distinguishable design elements were not primarily the structures of lines but other types of elements including 1) the distance between lines, 2) small and large empty spaces, 3) line uniformity, and 4) number of lines. This conclusion was from the fact that even though different models were constructed with different structures of lines, some of them still elicited the same feeling words. For instance, a model that had a structure that was curvilinear dominant (B9), a model that had a structure with an emphasis on diagonality (C13), and a model with a structure of radial burst (D20) elicited the same feeling word of strong. These models had other design elements that were the same: 1) even distance between lines, high frequency of lines, 2) small space between lines,3) line uniformity, and 4) large number of lines. As another example, a model that had a structure that were curvilinear dominant (B9) and another model that had a structure with an emphasis on diagonality (C13) both elicited the feeling word of confident. These latter two models also had the same other 4 design elements as above.

Hence, it can be concluded that models with 4 the above design factors elicited the same feelings of strong and confident even though their line structures were different.

The design elements that were easily distinguishable by touch on the 3-D models were distance between lines, line frequency, space between lines, line uniformity, and number of lines. As these elements were varied, the feeling words elicited from the corresponding models also varied. For instance, the feeling words busy, tense, friendly, gentle, sensitive, enjoyable, independent, natural, simple, comfortable, easy, and flexible were elicited from the models with the following kind of design factors: 1) uneven distance between lines, low frequency of lines, 2) large space between lines, 3) line non-uniformity, and 4) small number of lines. As another example, the feeling words strong, confident, manful, and delicate were elicited from the models with the following kind of design factors: 1) even distance between lines, high frequency of lines, 2) small space between lines, 3) line uniformity, and 4) large number of lines.

From the results, a group of 4 factors expressed a range of feelings while another group of 4 factors that were the opposite of the first group expressed another range of feelings. In our next study, the correlation between these factors will be investigated in detail so that they can be used directly by designers to construct textured surface components of packages or products.

In the first phase of the study, it was found that the elicited feeling words were not very different semantically. The reason that those words were not so semantically different was that the participants with non-design background appeared to lack diverse vocabulary for describing the models. For this reason, a future study should include only participants with design background in order to gain more diverse but accurate and usable feeling words that will be more beneficial for design work.

\section{Acknowledgments}

Arch.D. Program, in Multidisciplinary Design Research, Faculty of Architecture, King Mongkut's Institute of Technology Ladkrabang, Chalongkrung Road, Ladkrabang, Bangkok, Thailand. I am thankful to Mr Pratana Kangsadal for his revision of the English of this paper.

\section{References}

Becker, L., Rompay, T. J. L., Schifferstein, H. N. J., \& Galetzka, M. (2010). Tough package, strong taste: The influence of packaging design on taste impressions and product evaluations. Food Quality and Preference, 22, 17-23. https://doi.org/10.1016/j.foodqual.2010.06.007

Crilly, N., Moultrie, J., \& Clarkson, P. J. (2004). Seeing things: consumer response to the visual domain in product design. Design studies, 25(6), 547-577. https://doi.org/ 10.1016/j.destud.2004.03.001

Chavalkul, Y. (2003). Space lesson (Eds.). Thailand, Bangkok: Chulalongkorn University Publisher

Denscombe, M. (2010). The good research guide (4th ed.). New York, NY: McGraw-Hill 
Jirapinyo, O. (2015). Position a product and to convey its selling point. Teaching documentary. King Mongkut's Institute of Technology Ladkrabang, Thailand

Ludden, G. D. S., \& Schifferstein, H. N. J. (2009). Should Mary Smell Like Biscuit? Investigating Scents in Product Design. International Journal of Design, 3(3), 1-12.

Marlow, N., \& Jansson-Boyd, C. V. (2011). To touch or not to touch: that is the question. Should consumer always be encouraged to touch products and does it always alter product perception. Psychology \& Marketing, 28(3), 256-266. https://doi.org/10.1002/mar.20391

McDougall, A. (2010). Alcan produce Multi-Sensory packaging for luxury Market. Retrieved from http://www.c osmeticsdesign-europe.com/Packaging-Design/Alcan-produce-Multi-Sensory-packaging-for-luxury-market

McDougall, A. (2010). Multi-sensory packaging wins consumers'attention. Retrieved from http://www.cosmetic sdesign-europe.com/Packaging-Design/Multi-sensory-packaging-wins-consumers-attention

Ritnamkam, S., \& Chavalkul, Y. (2016). The Influence of Textured Surfaces of Cosmetic Packaging on Consumers' Feelings. Environment Behaviour Proceeding Journal, 1(3), 123-131. https://doi.org/10.21834/e-bpj.v1i3.357

Ritnamkam, S., \& Sahachiseree, N. (2012). Cosmetic Packaging Design: A Case Study on Gender Distinction. Procedia-Social and Behavioral Sciences, 50, 1018-1032. https://doi.org/10.1016/j.sbspro.2012.08.102

Smets, G. J. F., \& Overbeeke, C. J. (1995). Expressing tastes in packages. Design Studies, 16, 349-365.

\section{Appendix A}

\section{2-D designs}

A structure with an emphasis on horizontality and verticality (A structure)
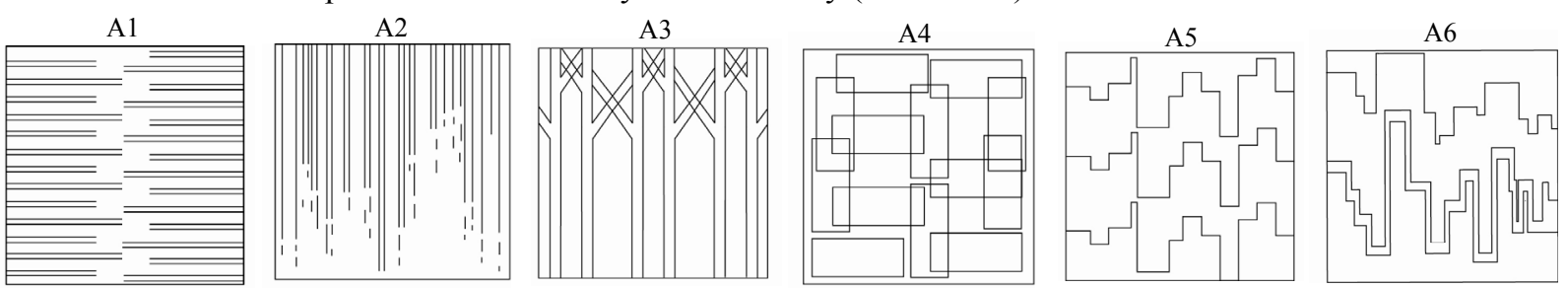

A structure that were curvilinear dominant (B structure)
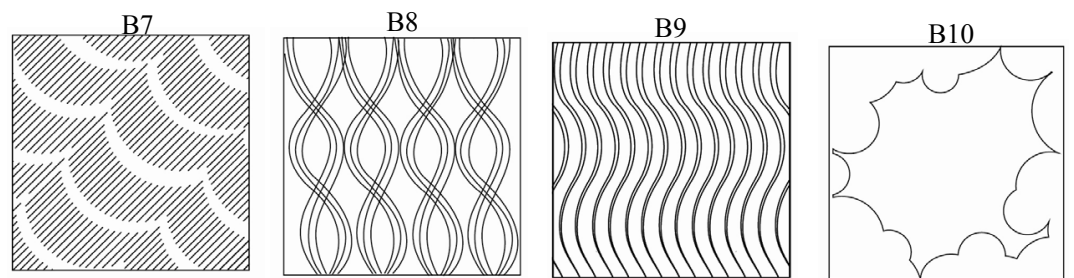

A structure with an emphasis on diagonality (C structure)

$\mathrm{C} 13$

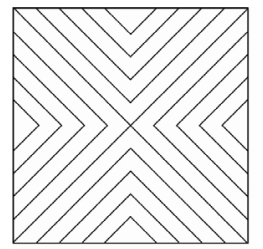

C14

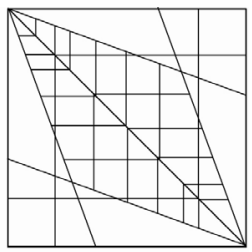

C15

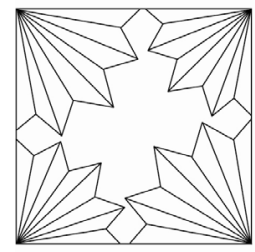

C16

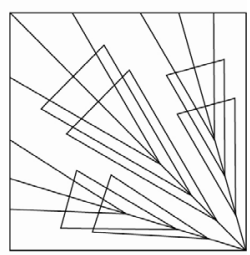

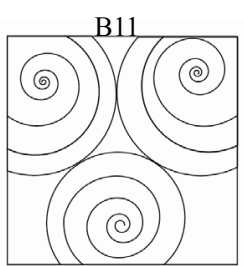

C17

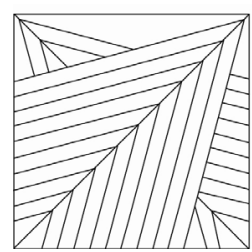

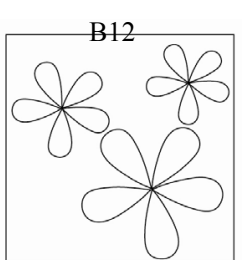

C18

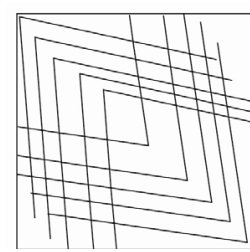

A structure with radial burst (D structure)

D19

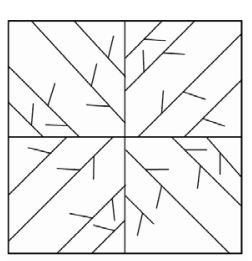

D20

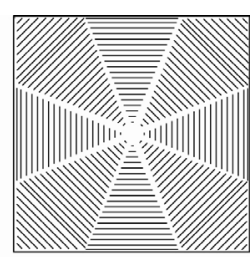

D21

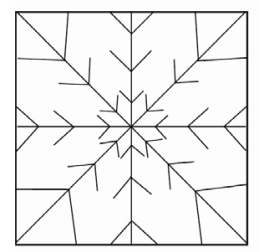

D22

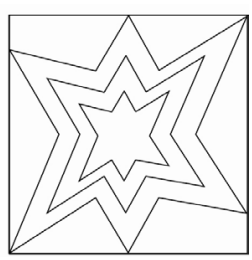

D23

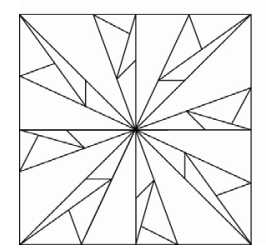

D24

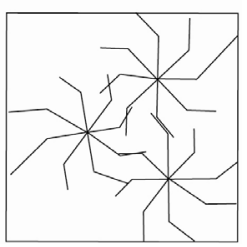


A structure with an emphasis on contrasting line orientation (E structure)

E25



E26

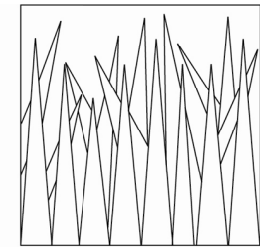

E27

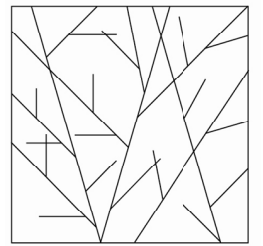

E28

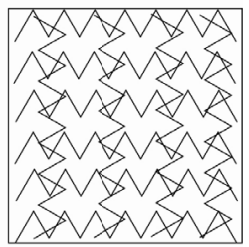

E29

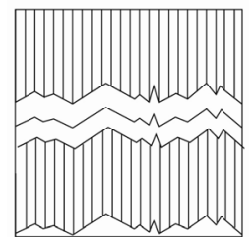

E30

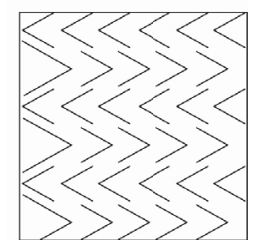

A structure with an even spread of lines (F structure)

F31

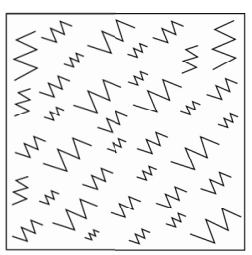

F32

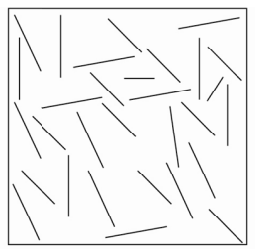

F33

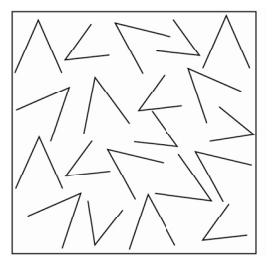

F34

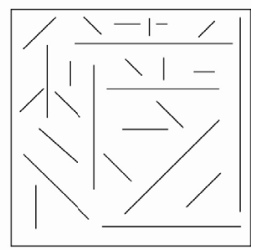

F35

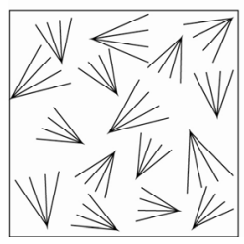

F36

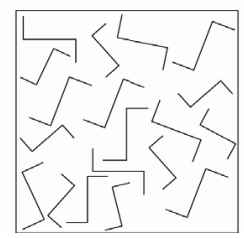

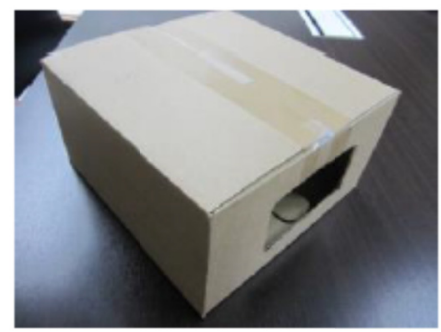

Figure 5. The hiding box 26x26x14 cm. in size, with holes on 2 sides $12.5 \times 7.5 \mathrm{~cm}$ in size
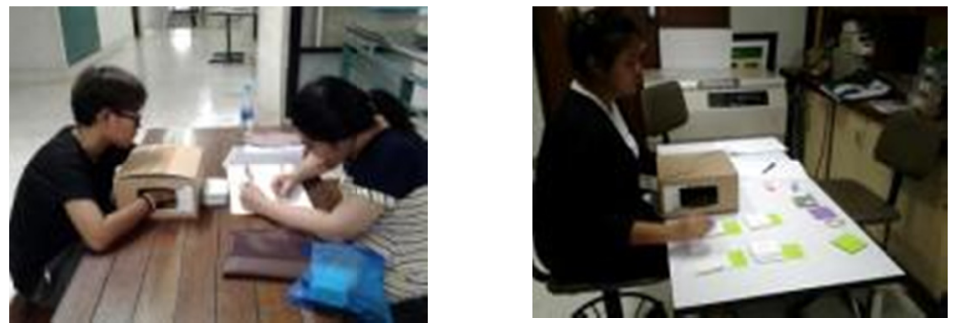

Figure 6. The site where the survey was made

\section{Copyrights}

Copyright for this article is retained by the author(s), with first publication rights granted to the journal. This is an open-access article distributed under the terms and conditions of the Creative Commons Attribution license (http://creativecommons.org/licenses/by/4.0/). 